\title{
Narrative development and gestures in different genres
}

\author{
Gökhan Özkayin \\ Institute of German Studies, University Koblenz-Landau, Germany \\ https://doi.org/10.36505/ExLing-2019/10/0038/000400
}

\begin{abstract}
This paper explores genre-specific diversities of verbal narratives in different situational contexts. The main purpose is to analyse the narrative development and the usage of manual gestures of German speaking children in the age of 6-10. Data analysis revealed that the quantity of co-speech gestures differs not only with the age of the speaker and the situational contexts but also with narrative genres.
\end{abstract}

Key words: narrative development, gestures, children, spoken language, multimodality

\section{Introduction}

The narrative genre or the inducement to tell a story causes and influences not only the structure but also recurrent patterns in children's narrations. Studies on gestures in discourse (e.g., McNeill 2005; Gullberg 2006) have shown that speakers build coherent discourse by using speech and co-occurring gestures during narratives.

The focus of this research is to analyse whether and to what extend different narrative genres effect the usage of gestures.

\section{Method}

The presented results are related to one of several experiments of an ongoing study. All experiments are recorded on video. The examined videos of children's narratives are recorded in two different settings: 1. presentations of self-created stories told as monologues in front of their classmates. 2. interactional narratives told to a single classmate. In the first setting the narrators tell picture stories or story continuations. In the second setting the variants of the stimuli are divergent. Children retell either an animated short movie with no verbal stimuli or they tell the continuation of a story they just listen to, so without visual stimuli.

Following stimuli were used in the depicted experiment below: 1. an animated short movie without speech. 2. An instruction to tell self-experienced narratives or to tell the continuation of a story they hear.

This leads to following contrastive situational contexts that are analysed in this paper: (i) monologues vs. interactional narratives (ii) fantasy stories vs. selfexperienced narratives. A wider scope of this study is on the one hand the investigation of verbal cohesive elements of speech that create a coherent

ExLing 2019: Proceedings of 10 $0^{\text {th }}$ International Conference of Experimental Linguistics, 25-27 September 2019, Lisbon, Portugal 
narration and on the other hand the non-verbal or implicational (e.g., bridging, presuppositions or framing) creations of coherent units. Several studies characterize these elements as one of the main indications for narrative development of children in elementary school (e.g., Boueke et al. 1995).

The variations in the data lead to investigations of several, related aspects of the interplay between gestures and verbal language, such as the syntax of discourse referents and possible co-referents as well as the effectiveness of cohesive gestures to create a coherent narration.

\section{Participants}

The investigations are based on a video-corpus of German-speaking children from elementary school that tell or retell different types of narrations. The videos were recorded and collected at one elementary school in Germany (Rheinland-Pfalz) in 2019. The 68 participating children were in the age of 6-10. Distribution of children by age: 6-7 (15 participants); 7-8 (12 participants); 8-9 (20 participants) and 9-10 (21 participants).

\section{Gestures}

A huge number of approaches exist to describe or define a gesture. In this study gesture is defined as the visible movement of any body part consciously or unconsciously made with the intention of communicating while speech is being produced (Calibris 2011). Still the focus in this experiment described below is on manual gestures. The combined use of speech and gesture develops, for example in the increase of rhythmic beat gestures with increasing narrative sophistication (Colletta 2004).

That's why special emphasis is on the quantity of discourse structuring gestures and co-speech iconic gestures. Different terminologies exist to describe the phenomenon of discourse structuring gestures: e.g., beats (McNeill 1992), discourse gestures (Müller 1998) or gestures with a parsing function (Kendon 2004). The term beat is preferred in this study. A simplistic definition of beat gestures describes them as non-referential and displaying a rhythmic behavior that is often accompanied by prosodic phenomenon. They also can assume a wide range of pragmatic functions. Whereas the term iconic gesture (McNeill 1985) refers to hand gestures that represent meaning that is related to the semantic content of the segments of speech they accompany.

\section{Data}

Because of significant differences in the length of the narratives the presented numbers display the average quantity of manual gestures per 50 words in a narrative. 
Table 1. Average quantity of manual beat gestures per 50 words in retellings of an animated short movie

\begin{tabular}{|l|l|l|}
\hline \hline Age & Monologue & Interactional \\
\hline $6-7$ & 0.21 & 0.34 \\
\hline $7-8$ & 0.28 & 0.48 \\
\hline $8-9$ & 0.44 & 0.89 \\
\hline $9-10$ & 0.71 & 1.02 \\
\hline \hline
\end{tabular}

Table 1 shows the increase of manual beat gestures with the age of the speaker. Apart from this the quantity of beats also increase in interactional situations when they tell a story to a single classmate who is indicating a prompt response during the interaction.

Table 2. Average quantity of iconic gestures per 50 words in retellings of fantasy stories vs. self-experienced narratives

\begin{tabular}{|l|l|l|}
\hline \hline Age & Fantasy & Self-exp. \\
\hline $6-7$ & 1.12 & 1.45 \\
\hline $7-8$ & 1.37 & 1.47 \\
\hline $8-9$ & 1.89 & 2.23 \\
\hline $9-10$ & 1.92 & 2.54 \\
\hline \hline
\end{tabular}

Table 2 shows the increasing of iconic gestures with the age of the speaker in fantasy stories as well as in self-experienced stories. Even if the amount of iconic gestures is significantly higher in self-experienced stories. Table 1 and 2 also shows that children were able to adapt their narration to the addressee and to the communicative context.

\section{Results}

It can be seen from the collected data that the narratives and especially the quantity of co-occurring gestures vary not only in different situational contexts but also with the application of diverse stimuli. Furthermore, the results of the study demonstrate that narrative development is accompanied by gestural development, too. Older children use manual gestures more often than younger children to structure information, for attributional uses, to introduce new discourse-referents or to refer to available discourse-referents.

The analyses demonstrate effects of cohesive gestures on subsequent discourse comprehension and production in children's narratives as it has been shown on other languages (for English: Goodrich Smith/Hudson Kam 2012; for Japanese: Sekine/Kita 2015).

Children's use of gestures related to narrative organization becomes more developed as children's narratives become more complex (Colletta et al. 2015). 
Additionally, gestures help children to boost their subsequent narrative performance.

\section{References}

Boueke, D., Schülein, F.; Büscher, H. 1995. Wie Kinder erzählen. Untersuchungen zur Erzähltheorie und zur Entwicklung narrativer Fähigkeiten. München, Fink.

Calibris, G. 2005. Eléments of meaning in gesture. Amsterdam, John Benjamins.

Colletta, J. M. (2004). Le développement de la parole chez l'enfant âgé de 6 à 11 ans. Corps, language et cognition. Sprimont, Mardaga.

Colletta, J.-M., Guidetti, M., Caprici, O., Cristilli, C. 2015. Effects of age and language on co-speech gesture production: an investigation of French, American, and Italian children's narratives. Journal of child language 42, 122-145.

Goodrich Smith, W., Hudson Kam, C.L. 2012. Knowing 'who she is' based on 'where she is': The effect of co-speech gesture on pronoun comprehension. Language and Cognition, 4-2, 75-98.

Gullberg, M. 2006. Handling Discourse: Gestures, Reference Tracking and Communication Strategies in Early L2. Language Learning, 56, 155-196.

Kendon, A. 2004. Gesture. Visible Action as Utterance. Cambridge, University Press.

McNeill, D. 1985. So you think gestures are nonverbal? Psychological Review 92 (3), 350-371.

McNeill, D. 1992. Hand and Mind. What Gestures Reveal about Thought. Chicago, The University of Chicago Press.

McNeill, D. 2005. Gesture and Thought. Chicago, University of Chicago Press.

Müller, C. 1998. Redebegleitende Gesten. Kulturgeschichte - Theorie Sprachvergleich. Berlin, Arone Spitz GmbH.

Sekine, K., Kita, S. 2015. Development of multimodal discourse comprehension: cohesive use of space by gestures. Language, Cognition and Neuroscience, 30, 1245-1258. 